\title{
PROPOSTA DE INTERVENÇÃO PARA O ENSINO DA LÍNGUA MATERNA: ANÁLISE LINGUÍSTICA DE ASPECTOS VERBAIS EM ARTIGO ASSINADO
}

\author{
Lenir Maria ROSSAROLA \\ (Universidade Federal de Santa Catarina) \\ lenir.rossarola@ufsc.br \\ Nara Caetano RODRIGUES \\ (Universidade Federal de Santa Catarina) \\ nacaetano@yahoo.com.br
}

\begin{abstract}
Resumo: A articulação entre as práticas de linguagem no ensino de língua tem se mostrado um desafio no trabalho de elaboração didática dos conteúdos na disciplina de Língua Portuguesa. O estudo aqui apresentado é uma proposta de intervenção no ensino de língua materna, em turma de alunos do Ensino Fundamental II, com enfoque no gênero artigo assinado, incluindo análise linguística sobre aspectos verbais durante pelo menos um mês de trabalho em aulas regulares. Destacamos a importância da sistematização dos conteúdos, além do estudo das características discursivas e estruturais do gênero em questão. A proposta consiste em leitura/escuta de textos no gênero artigo assinado, encontrados em jornais e também em textos produzidos por alunos de mesmo nível escolar, seguida de análise linguística do fenômeno gramatical aspectos verbais e produção textual com posterior divulgação. Para tanto, buscamos fundamentação teórica em Antunes (2003), Menegassi (2003), Bortoni-Ricardo (2005), Mendonça (2005), Geraldi (2012), Bezerra \& Reinaldo (2013), Castilho (2014), dentre outros. Esse artigo é um desdobramento do projeto de intervenção que constitui uma das produções realizadas na disciplina Estratégias do Trabalho Pedagógico com a Leitura e a Escrita, parte da grade curricular do Programa de Mestrado Profissional em Letras Profletras.
\end{abstract}

Palavras-chave: Gênero artigo assinado. Análise linguística. Aspectos verbais.

\section{AN EDUCATIONAL INTERVENTION PROPOSAL IN MOTHER LANGUAGE TEACHING: LINGUISTIC ANALYSIS OF VERBAL ASPECTS IN A SIGNED ARTICLE}

Abstract: The articulation of different language practices in language teaching has been a challenge in what relates the didactic organization of contents in the Portuguese Language class. This study, which is an educational intervention proposal in Portuguese language teaching as first language in Elementary School II classes, focuses in a textual genre, namely the signed article. It includes linguistic analysis on the verbal aspects found in the source text present in teaching activities 
that were implemented during one month. We highlight the importance of content systematization, along with the study of discursive and structural features of the genre. The intervention proposal consists of reading/listening activities involving gender signed articles, found in newspapers as well as in texts produced by students. These texts are submitted to linguistic analysis of the grammatical phenomenon, the verbal aspects and text production. We use theoretical foundations stemming from the work of: Antunes (2003), Menegassi (2003), Bortoni-Ricardo (2005), Mendonça (2005), Geraldi (2012), Bezerra and Reinaldo (2013), Castilho (2014), among others. This article constitutes the unfolding of an educational intervention proposal produced for the subject "Estratégias do trabalho pedagógico com a leitura e a escrita" which is part of the Mestrado Profissional em Letras (PROFLETRAS)

Keywords: Genre. Signed article. Linguistic analysis. Verbal aspects.

\section{Introdução}

A língua é um produto vivo, proveniente das interações sociais em determinados contextos e situações e, sendo assim, só existe de fato nos contatos sociais, na interlocução entre os sujeitos. Estudar a língua, segundo Geraldi (2012, p. 42) é "tentar detectar os compromissos que se criam por meio da fala e as condições que devem ser preenchidas por um falante para falar de certa forma em determinada situação concreta de interação".

Podemos transportar esta ideia à escrita, que representa a materialidade da fala - o texto -, pois ela apresenta certos compromissos e condições para dizer aquilo que se quer de fato dizer de forma escrita. Fazemos uso de certas convenções gramaticais para, dependendo da finalidade, escrever um texto, em nossa língua, que transmita o sentido que desejamos a certo público.

Em estudos sobre o ensino de língua materna, é sempre uma preocupação trabalhar com oralidade e escrita, principalmente. E é considerando tal materialidade da língua em textos que proporemos atividades, em intervenção, em uma seção deste artigo, envolvendo leitura/escuta, escrita, análise linguística e produção textual.

O ensino de língua materna, de acordo com os Parâmetros Curriculares Nacionais de Língua Portuguesa [PCN-LP] (BRASIL, 1998) propõe o estudo da língua através do texto, pela abordagem discursiva, promovendo o estudo de diversos gêneros a cada ano escolar. No PCN-LP (BRASIL,1998, p. 23), consta que "O discurso, quando produzido, manifesta-se linguisticamente por meio de textos. 
Assim, pode-se afirmar que texto é o produto da atividade discursiva oral ou escrita que forma um todo significativo e acabado, qualquer que seja sua extensão". É nesta linha que pretendemos conduzir nossa proposta.

Antunes (2003, p. 110) salienta a importância de definir o objeto de estudo da aula de Português, pois é este objeto que vai "condicionar a escolha dos itens, os objetivos com que os abordamos e a escolha das atividades pedagógicas". O objeto é o texto, então é ele "que vai conduzindo nossa análise e, em função dele, é que vamos recorrendo às determinações gramaticais, aos sentidos das palavras, ao conhecimento que temos da experiência" (ibid.). Segundo a autora, ensinar a língua materna deve pretender "ampliar a competência do aluno para o exercício cada vez mais pleno, mais fluente e interessante da fala e da escrita, incluindo, evidentemente, a escuta e a leitura" (ibid.).

Assim sendo, o presente artigo traz uma proposta de intervenção para o ensino de língua materna, a nossa Língua Portuguesa, procurando analisar os aspectos verbais utilizados em textos escritos no gênero artigo assinado, buscando privilegiar momentos, conforme referido acima, de leitura/escuta, de oralidade, de análise de fenômeno gramatical e de escrita. Para tanto, pretendemos propor leitura/escuta de textos neste gênero - artigo assinado -, realizar com os alunos análise linguística dos aspectos verbais, bem como encorajá-los a produzirem textos que tragam, pelo menos, traços do gênero artigo assinado, para posterior publicação.

Pensar este assunto é muito importante uma vez que objetivamos certa ação do professor no ensino da língua materna. Concordamos com Menegassi (2003) com relação às ações do professor de Português: análise-reflexão-reformulaçãoação sobre sua prática, encarando a produção textual como processo e não como produto a ser avaliado meramente. Além disso, o autor ressalta a observância aos elementos a serem considerados na produção de um texto, quais sejam: finalidade, especificidade do gênero, lugares preferenciais de circulação e interlocutor eleito.

O professor de Português se ocupa em pensar sua aula, refletindo movimentos autorais que trazem amalgamados os anos de experiência, o conhecimento adquirido na área e toda a gama de criatividade para tornar sua aula um acontecimento, que reflita sobre a nossa língua e proporcione a construção de conhecimentos. Teoria e prática se misturam na elaboração das aulas, de acordo com o excedente de visão do professor, conforme coloca Rodrigues (2011, p. 184), 
pois o professor, ao preparar a "elaboração didática, está lidando com algo que [...] já ressignificou para a/na prática".

A fim de oferecer espaço de discussão sobre a língua em uso, representativa das interações materializadas em textos, a organização deste estudo traz uma proposta de intervenção para o ensino em língua materna, centrada no trabalho com o gênero artigo assinado, com enfoque na análise linguística de aspectos verbais. A proposta está constituída por quatro seções, dispostas na seguinte ordem: $O$ ensino de língua materna, Análise linguística, Aspectos verbais e Proposta de intervenção. A proposta de intervenção conta com atividades de leitura, escuta, escrita, análise linguística e produção de artigos assinados. Para encerrar, apresentamos algumas Considerações finais.

\section{O ensino de língua materna}

Uma das grandes preocupações de pesquisadores da linguística aplicada é a forma de condução nas ações voltadas ao ensino da língua materna. Os Parâmetros Curriculares Nacionais de Língua Portuguesa traçam diretrizes e alguns autores as corroboram, como veremos a seguir.

Mendonça (2005, p. 113) salienta que há certo consenso quanto aos principais eixos do ensino de Português - leitura e escrita, dentre os estudiosos da língua. Inclusive os PCN-LP (1998, p. 23) ressaltam a centralidade do texto:

Atualmente, exigem-se níveis de leitura e escrita diferentes dos que satisfizeram as demandas sociais até há bem pouco tempo - e tudo indica que essa exigência tende a ser crescente. [...] Dentro desse marco, a unidade básica de ensino só pode ser o texto.

De acordo com os Parâmetros Curriculares Nacionais de Língua Portuguesa, a produção textual escrita considera algumas condições: finalidade, especificidade do gênero, lugares preferenciais de circulação e interlocutor eleito. A compreensão de tais condições remete ao trabalho com o gênero textual/discursivo.

Discutindo a importância de apontar as condições de produção nos comandos de produção de textos, Menegassi (2003, p. 58) destaca que "ao se definir a finalidade da produção, opta-se pelo tipo de gênero textual, que, por sua vez, abarca o lugar de circulação do texto e, consequentemente, impõe um tipo de interlocutor". O autor acredita que os comandos transmitidos/dirigidos pelo professor precisam 
estar coerentes com estas condições da produção para levar o aluno a uma escrita situada.

O gênero textual a ser produzido pelo aluno, para Menegassi (2003), deve ser traduzido pela presença dos elementos que são referidos como relevantes na construção do texto nos PCN-LP de $3^{\circ}$ e $4^{\circ}$ ciclos do ensino fundamental (BRASIL, 1998, p. 58): a finalidade da produção daquele texto, ou seja, o objetivo da produção escrita; a especificidade do gênero textual a ser escrito; o seu lugar de circulação, devendo, então, observar qual a linguagem a ser utilizada; e a delimitação do interlocutor, ou seja, a quem destinamos o texto ou quem será o leitor. O autor pontua, a respeito do último elemento, que "A determinação do interlocutor aponta o tipo de linguagem empregada no texto, a maneira de expor o assunto, em virtude do gênero escolhido e do lugar de circulação, conduzindo o autor a uma construção mais adequada do texto" (MENEGASSI, 2003, p.57).

O uso do texto enquanto pretexto para aplicação de exercícios de gramática não é coerente com esta proposta. A aprendizagem do aluno não é contemplada de maneira satisfatória ao considerarmos a gramática acima de qualquer análise mais profunda do texto. Os estudos que se atrelam basicamente a aspectos gramaticais não colaboram para o trabalho com textos em nenhum gênero. Portanto, as aulas tradicionais de gramática não são próprias ao ensino de língua materna que pretende contemplar o trabalho com os gêneros textuais/discursivos, uma vez que o teor do texto e o que ele representa ficam relegados a segundo plano.

Acreditamos que a análise da língua em uso em determinado gênero do discurso permite a compreensão de tal uso para o texto fazer o sentido que pretendemos. Sendo que a produção textual em determinado gênero passa pelas condições de produção, opções de circulação e situações de interlocução possíveis. Assim, a proposta de intervenção trazida neste artigo é baseada em uma sequência de atividades que privilegiam o estudo do gênero artigo assinado.

Para a melhor compreensão da proposta, é de extrema relevância conhecer o que vem a ser a análise linguística, traduzida pelas possibilidades de análise do uso da língua no curso da história e no uso que fazemos dos fenômenos linguísticos. $\mathrm{Na}$ sequência, algumas pinceladas sobre análise linguística. 


\section{Análise linguística}

A expressão "análise linguística" surgiu na década de 80 , cunhada por Geraldi ([1982]2012) na esfera da academia, e posteriormente foi abarcada pelos PCN-LP, na década de 90, de acordo com Bezerra e Reinaldo (2013, p. 52).

Geraldi ([1982]2012, p. 73) propõe o trabalho de sala de aula com "reflexão linguística", inclusive com os textos dos próprios alunos, nos quais a análise da língua ocorrerá na observação da construção de seus textos, sendo que, em caso de problema de língua, a reescrita será recomendada, acontecendo semelhante a uma autocorreção que parte de um erro.

Os eixos norteadores das atividades didáticas, pós PCN-LP, segundo Bezerra e Reinaldo (2013, p. 33), sugerem o estudo da língua materna, pautado "na língua falada, na leitura, na escrita e na análise linguística". E, mesmo a expressão "análise linguística" não estando presente em livros didáticos ou em alguns manuais de ensino da língua, existe uma preocupação com "a ideia de reflexão sobre o uso" da língua (ibid.).

Bezerra e Reinaldo (2013, p. 51) pontuam, a respeito da evidência de alteração no foco do estudo da língua, a relevância de passarmos "de uma preocupação em atender à norma padrão estabelecida, para uma preocupação em atender à diversidade de usos em função das necessidades comunicativas".

Da mesma forma, buscaremos construir nossa proposta vinculada à reflexão do sentido do texto através da análise linguística, tendo como elemento-instrumento de estudo o texto; e mais, se texto é produto social, é discurso, segundo Wachowicz (2012, p. 22):

[...] as esferas de atividade social humana têm suas opções de comunicação, que esses processos são adquiridos naturalmente e que a escola tem o papel de desvendar ao aluno as experiências complexas de letramento -, o elemento-chave para o trabalho com o texto em sala de aula passa a ser o gênero.

Os gêneros textuais são fruto das interações humanas e se traduzem em textos materializados em evento de comunicação, portanto bastante dinâmicos. Bakhtin (2011 [1979, 1992, 2003], p. 263) coloca que os gêneros são "tipos relativamente estáveis de enunciados". E Marcuschi (2002, p. 19) acrescenta que são "maleáveis, dinâmicos e plásticos". É nesta perspectiva que tomamos o gênero como base do estudo de texto em nossa proposta de intervenção. 
Os gêneros possuem estruturas linguísticas e finalidades discursivas que os distinguem. Ocorre um trabalho linguístico entre os sujeitos nas relações sociais de interação verbal na escolha de determinados recursos estilísticos para viabilizar seu projeto de dizer. Neste trabalho linguístico de produção de discursos, os sujeitos agem sobre a linguagem, conduzindo os recursos linguísticos a fim de dar sentido ao enunciado. Estes usos de recursos linguísticos envolvem os aspectos verbais, foco da nossa proposta de trabalho com análise linguística.

Salientamos a importância de trabalhar, de forma articulada, a oralidade, a leitura e a gramática, a fim de desenvolver competências em práticas de leitura, produção textual e análise linguística, tendo como base o texto de determinado

gênero. Antunes (2003, p. 121) destaca que "mesmo quando se está fazendo a análise linguística de categorias gramaticais o objeto de estudo é o texto" (grifos da autora). Adiante, a autora acrescenta que "pela análise dos usos da língua entendese mais e melhor o funcionamento das unidades da gramática" (ibid.). É importante analisar o funcionamento das categorias na construção de sentidos através de análise/reflexão linguística.

Pelo fato de os indivíduos se relacionarem com o meio através de gêneros, escolhemos determinado gênero para preparar nossa intervenção. No caso da proposta aqui apresentada, o gênero é o artigo assinado, no qual focalizaremos a análise linguística, levando à reflexão do uso do fenômeno linguístico aspecto verbal.

\section{Aspectos verbais}

Esta seção complementa o objeto deste estudo, remetendo à parte de um conteúdo de ensino mais específico. Vamos tratar sobre o fenômeno do aspecto verbal na língua portuguesa, implicando na relação direta dos aspectos com o tempo verbal, uma vez que o verbo não é mais visto exclusivamente como um objeto de estudo da morfologia e da sintaxe e sim como foco de estudos de várias áreas interligadas: a semântica, a pragmática, a retórica, a teoria da argumentação.

O fenômeno verbal é muito mais que apenas uma palavra que exprime ação, estado ou fenômeno da natureza, de acordo com as categorias de modo, tempo, pessoa, número e voz. O verbo passa a ser estudado pela noção de tempo e 
aspecto, situadas no âmbito dos estudos da semântica. A utilização deste ou daquele tempo verbal, expressando este ou aquele aspecto verbal, acontece conforme a vontade do locutor/escritor, daquilo que ele quer expressar, do sentido que ele quer dar a seu texto, segundo sua intenção discursiva e de acordo com o gênero a que se propôs escrever.

Segundo Binnick (1991, p. 32, apud VARGAS, 2011, p. 20), o termo aspecto é:

[...] uma tradução emprestada do russo vid, e vidé da mesma família dos termos em inglês view e vision, enquanto a raiz original de "aspecto" é spect, "ver", "olhar", do latim spex, que remontaria à raiz indo-europeia spek, "olhar", "observar"; daí "espectador".

A procedência etimológica do vocábulo remete à definição de aspecto como "qualidade que se dá ao tempo", como propriedade que uma forma verbal adquire de desvendar uma ação, um estado, ou o que quer que o sentido de um verbo possa expressar. O termo teria sido importado da gramática do eslavo no início do século XIX e tornou-se parte da tradição gramatical do ocidente.

No curso da história das línguas indo-europeias, o aspecto foi perdendo a importância, na medida em que o tempo se estabeleceu como categoria principal na expressão do verbo. No latim, o sistema verbal constituiu-se sob dois grandes temas: o presente e o perfeito. O perfeito acumulou as funções do aoristo e as do perfeito. O sistema tornou-se bipartido, criando-se uma nítida oposição de caráter temporal entre os dois temas: a do presente, denominado infectum (ação imperfeita) e o do pretérito, chamado perfectum (ação consumida). Os tempos do infectum revelam marcas do aspecto imperfeito/durativo e os do perfectum do aspecto perfectivo/resultativo.

Conforme explica Travaglia (2003), o aspecto é uma categoria verbal ligada ao tempo para referir-se à ideia geral e abstrata do tempo, sem consideração de sua indicação pelo verbo ou qualquer outro elemento da frase. O tempo é considerado uma categoria dêitica (externa à situação). Já a categoria de aspecto não pode ser considerada dêitica, uma vez que se refere à situação em si, à duração, à qualidade que se dá ao tempo.

As formas verbais não podem ser analisadas apenas em sua constituição morfológica ou por meio de sua função sintática. Importa verificar em que medida elas contribuem para essa construção de sentido dos textos e o quanto refletem a intenção do sujeito que as seleciona para comunicar-se. Os termos acessórios das 
orações (especialmente dos adjuntos circunstanciais de tempo, modo, intensidade, etc.) acompanham as formas verbais e acrescentam nuances de movimento ou de aspecto e contribuem para a formação de sentidos dos enunciados.

As categorias de tempo e aspecto verbal podem denotar as mais variadas intenções de quem as utiliza: tornar os fatos mais reais, prolongá-los no tempo, promover uma visão "espacial" dos acontecimentos, enfim, persuadir, convencer, influenciar a pessoa com quem ocorre interação. A intenção de persuadir o leitor, de buscar adesão, convencimento é o que se entende como ato de argumentar.

$\mathrm{O}$ ato de argumentar relaciona-se com a noção de sujeito do discurso (a subjetividade), com a noção de tempo (a temporalidade) e com a noção de aspecto (aspectualidade), que devem ser analisadas como processos de formação de sentido, permitindo ao leitor a compreensão de determinado gênero do discurso.

Neves (2000) analisa os verbos aspectuais em perífrases ou locuções: (a) inceptivo, indicando início de evento (Exemplos: passou a aguardar, pus-me a caminhar); (b) cursivo, indicando desenvolvimento do evento (Exemplos: estava falando, continuam lutando); (c) habitual, indicando hábito (Exemplos: vive fazendo, anda lendo); (d) progressivo, indicando continuidade, progressão (Exemplos: está evoluindo, vai diminuindo); (e) terminativo ou cessativo, indicando término do evento (Exemplos: parou de falar, basta de proteger); (f) resultativo, indicando resultado de evento (Exemplos: está resolvido, está falado); e (g) iterativo ou frequentativo, indicando repetição de evento (Exemplos: tenho saído, costuma tentar).

Azeredo (2013) apresenta o estudo sobre aspecto verbal, trazendo o conceito de aspecto e algumas distinções aspectuais em Português. O autor traz também a classificação dos aspectos segundo o que expressam as ações. Por exemplo: comeu [ação perfectiva, concluída e unitária] $X$ comia [ação imperfectiva, não concluída e habitual]. O processo da duração é representado pelos aspectos conclusivos e os não-conclusivos.

Castilho (2014) pontua os aspectos, trazendo explicações sobre o sentido e respectivos exemplos: o aspecto imperfectivo - (a) o imperfectivo inceptivo (Exemplos: Começa a andar, pôr-se a, pegou a falar), (b) o imperfectivo cursivo (Exemplos: estava falando, está crescendo, tem brincado bastante) e (c) 0 imperfectivo terminativo (Exemplos: acabar de, terminar de, cessou de trabalhar); o aspecto perfectivo - (a) perfectivo pontual (Exemplos: encontrei, amarraram, 
absorveu completamente) e (b) perfectivo resultativo (Exemplos: ficou muito bonito, estão corrigidas); e o aspecto iterativo (Exemplos: tenho ido, raramente eu como, normalmente a gente tira).

De um modo geral, os gramáticos, mesmo, por vezes, com nomenclaturas distintas, chegam à mesma compreensão dos aspectos verbais utilizados na língua, pois estes acabam trazendo o mesmo sentido ao verbo, segundo o aspecto. É importante frisar aqui, no caso da proposta de intervenção, presente na próxima seção, que, além da questão gramatical, o uso dos aspectos verbais nos textos ocorre como produto das interações, revelando as intenções discursivas presentes nos textos do gênero artigo assinado.

\section{Proposta de intervenção}

A proposta de intervenção, aqui formulada e exposta, foi planejada com base na leitura de vários textos de um determinado gênero textual e em análise linguística, refletindo sobre os aspectos verbais e o sentido que passa o tempo verbal neste gênero. Prevê, pelo menos, um mês de trabalho, ocupando quatro a cinco períodos semanais de aula (conforme organização escolar) em turmas de $8^{\circ}$ e 9ำ ano (mais especificamente, tendo em vista o gênero escolhido).

A intervenção inclui a leitura de artigos assinados encontrados em jornais de circulação na escola em questão, como Riovale, Gazeta do Sul, Correio do Povo e Zero Hora, a fim de analisar o estilo do gênero, suas características discursivas, a forma composicional e o tema. Após, será realizada a leitura de artigos produzidos por alunos de nível escolar equivalente - $8^{\circ}$ ano. Tais artigos foram escritos por alunos de uma escola, no estado de Santa Catarina, como resultado de um trabalho desenvolvido sob mediação de Maieski (2005, p. 210). Não consideramos que o conhecimento deva ser comparado, a escolha se deve ao fato de contar com vários textos de opinião relacionados ao mesmo tema - celular - e de haverem sido escritos por alunos. A seguir, propomos produção textual neste mesmo gênero. Os alunos buscarão informações acerca do tema escolhido, traçarão um plano de organização das ideias para, então, escrever o texto, o qual passará por revisão e reescrita, caso necessário. Depois, sugerimos algumas atividades como práticas de 
letramento com análise linguística a fim de possibilitar o ensino e a aprendizagem sobre aspecto verbal.

As aulas com leitura de artigos assinados de jornais e de leitura de artigos assinados de alunos, produção e análise linguística sobre aspectos verbais estão divididas em cinco momentos: dois para leitura e análise do gênero, com roteiro para reflexão e roda de conversa; um para a análise linguística; mais um contendo a sistematização do conteúdo aspectos verbais; outro para preparar a produção textual; e mais outro, o momento final de divulgação das produções dos alunos.

O primeiro momento será a motivação inicial com a leitura de artigos assinados presentes nos jornais que a escola dispõe, pois são de acesso fácil. Os jornais ficam na biblioteca da escola. Aqui, o professor pode montar grupos de trabalho e orientar uma discussão/debate envolvendo questões que ajudem a entender o funcionamento do gênero, a partir da sua análise em diferentes jornais.

A leitura de artigos veiculados em jornais, encontrados na biblioteca da escola, prevê reflexões que levam a percepções como: onde se encontram publicados, quem escreveu e quem seria o público leitor provável, observando se os temas atuais são tratados de forma tendenciosa, ou seja, de acordo com determinada linha editorial do jornal. Todo este trabalho de descoberta e reflexão deve ser mediado pelo professor. As discussões são importantes para 0 entendimento das regularidades do gênero artigo assinado (gênero da esfera jornalística, com tema, composição e estilo próprios ${ }^{1}$ ). A leitura e as discussões podem ocupar um período ou dois, dependendo do número de artigos lidos pelos alunos e das discussões que porventura surgirem.

A orientação pode ser de leitura e de releitura para pensar sobre o gênero. Os alunos leem e releem buscando respostas para questões levantadas pelo professor em roteiro de análise para compreender o momento histórico, a forma de construção, etc.

Uma sugestão de roteiro para debate pode envolver o pensar sobre: o local deste gênero no jornal, por quem foi escrito, quando foi escrito, quem lê esse texto, por que foi abordada tal temática, como é organizado o texto, de onde partem as

\footnotetext{
1 Rodrigues (2000, p. 216), fundamentada na concepção bakhtiniana de gênero, aponta alguns aspectos relevantes para a compreensão da constituição e funcionamento do artigo assinado: "função discursiva específica na esfera jornalística, concepção de autor e destinatário, modo de abordagem do tema, estilo e composição próprios". A pesquisa da autora é uma referência importante para subsidiar o estudo desse gênero.
} 
informações que constam no texto, quais as palavras e recursos linguísticos utilizados na construção, como o texto está organizado no suporte jornal e se há diferenças na exposição do gênero entre os diferentes jornais.

Na sequência, em um segundo momento, o professor pode dividir as atividades em oralidade e escrita. A oralidade fica a cargo da leitura de texto no grupo e da discussão posterior; e a escrita se fixa no destaque das características do gênero. Serão ocupados dois períodos, um período para leitura e escrita de elenco de características e outro para as reflexões em roda de conversa.

O professor distribui cópia dos artigos produzidos por alunos de ano escolar equivalente (MAIESKI, 2005), um texto a cada grupo, todos os textos abordando o uso do celular, para a leitura e análise da construção do texto. O roteiro referido anteriormente pode servir à reflexão sobre as características presentes nos artigos dos alunos. Os questionamentos serão debatidos oralmente, oportunizando a socialização de ideias/opiniões.

Após o debate sobre os escritos dos alunos, o professor propõe que construam, escrevendo no caderno, um elenco de regularidades presentes a fim de apontar para as condições de produção, a forma composicional, o teor temático e os recursos linguísticos utilizados. Os questionamentos levantados pelo professor, no roteiro do primeiro momento, servem ainda para montagem do elenco de características e, consequentemente, para facilitar a compreensão do gênero.

O professor pode auxiliar os grupos de alunos, em particular, indo até a classe, tecendo comentários ou até mesmo colaborando com a escrita. Cada grupo vai realizar apontamentos para a realização posterior de uma roda de conversa. A organização da roda implica arrumação da sala com cadeiras dispostas em formato de círculo. Nessa etapa, os alunos vão socializar, com os colegas, lendo ou socializando oralmente os apontamentos. O roteiro, lançado lá no início, pode ser observado para conduzir a conversa. Também é importante permitir que os alunos, livremente, emitam suas opiniões sobre o tema e forma de construção do texto (podendo contar sobre o que leram e/ou falar sobre as características do texto).

O terceiro momento traz atividades de análise linguística sobre aspectos verbais a serem realizadas com os textos dos alunos, tratando o verbo como um dos mecanismos essenciais da língua, que permite ao sujeito refletir sobre o fenômeno verbal, sobretudo como um fato semântico-discursivo, passível de promover a 
interpretação, o debate, a pesquisa e a troca de experiências. Aqui o professor pode optar por eleger alguns ou somente um texto para conduzir as atividades de análise linguística. Escolher o texto que cada grupo recebeu para leitura e análise.

A atividade pode começar com a seleção dos verbos que exprimem ação ou movimento, destacando-os nos textos, uma vez que os alunos já possuem este conhecimento de anos anteriores. Assim, meio período é suficiente para cada grupo destacar os verbos nos textos. Lembrando que cada grupo recebeu um texto para a leitura inicial, portanto é neste texto que destacarão os verbos. O professor, para facilitar a atividade, pode dispor de cópia do texto do grupo a cada aluno.

Após a seleção dos verbos que exprimem ação ou movimento, o professor faz uma explanação sobre os sentidos que podem ser expressos pelas ações, remetendo ao emprego de cada tempo verbal. Os tempos verbais já foram estudados no 6ำ ano escolar. Assim sendo, os alunos terão condições de voltar aos verbos destacados e analisar o sentido destes. Meio período é suficiente para esta atividade. Sem necessidade de sistematização das classificações dos aspectos verbais, o aluno pode inferir qual o sentido que eles apresentam no texto. $O$ professor pode utilizar estratégias diversas para incentivar a descoberta do sentido de cada aspecto verbal encontrado no texto, ocupando mais um período de aula.

O aluno, até aqui, destacou verbos e analisou o sentido que possuem. Agora, o professor pode sistematizar o conteúdo relacionado a aspectos verbais, apontando as possibilidades de sentido tratadas pelos gramáticos. A seguir, em outra aula, analisar, na linha do tempo, a frequência do tempo verbal presente no texto. Depois, reescrevê-lo, alterando o tempo para o passado, a fim de observar o que muda nas relações de sentido e se o gênero foi prejudicado com tal mudança de tempo.

Ainda, o professor pode propor que sejam observados outros recursos linguísticos utilizados neste gênero, não se fixando tão somente na questão dos aspectos verbais. Há a possibilidade de analisar como ocorre a construção do ponto de vista, se o autor utiliza citação da palavra de outrem, se inclui exemplos, qual a seleção vocabular, que adjetivações são empregadas, etc.

Posteriormente, em um quarto momento, a proposta é a produção textual de artigo assinado, colocando a opinião individual (o seu ponto de vista) sobre o tema: uso do celular. O professor combinará com os alunos posterior divulgação, inclusive 
o local. Dois períodos permitem o planejamento ${ }^{2}$ e a conclusão da escrita, inclusive se necessário reformular algo no texto.

É importante se certificar de que os alunos tenham percebido as regularidades do gênero artigo assinado (condições de produção, circulação e recepção) para então utilizar em sua produção. Esta parte poderá contar com a reescrita do texto, se necessário, seguindo apontamentos do professor para melhorar a escrita, por exemplo, e aconteceria fora do horário de aula.

Para a produção textual, o professor pode orientar que escrevam observando as características do gênero e o interlocutor/leitor. Como sugestão de orientação do professor, o enunciado da atividade poderia ser o seguinte: "Aproveitando as discussões sobre o tema 'celular' e observando o elenco de características do gênero artigo assinado, produza um texto com a mesma temática, podendo ser veiculado em suporte virtual e real, e neste mesmo gênero. Antes de partir para a redação, trace um esquema que oriente as informações em seus escritos".

O material produzido, em um quinto e último momento, merece publicação, após avaliação do professor para propor ou não a reescrita. Esta produção pode ser publicada de modo virtual, em blog, ou pode fazer parte de um painel na escola, enfim, pode ser publicado/divulgado de alguma maneira. O preparo do painel e a colocação dos textos nele pode ocupar um período. Caso a opção seja divulgação via blog, será necessário tempo maior para as atividades de letramento digital.

Além de todas estas atividades, culminando nessa produção com divulgação, poderia ser necessária, antes da publicação, nova reescrita do texto. Seria, então, solicitada a entrega do texto ao professor para uma avaliação de problemas de escrita, adequação ao gênero, aspectos da textualidade (coesão, coesão, coerência, progressão temática entre outros). Cabe aqui a avaliação do professor, após ler os textos de seus alunos, e a posterior devolução com encaminhamentos para reescritura e, finalmente, para publicação.

A seguir, o esquema da atividade:

Momento 1: Motivação inicial pela leitura de textos veiculados em jornais disponíveis na biblioteca da escola

- Leitura, em grupo, dos artigos assinados nos diferentes jornais (Riovale, Correio do Povo, Gazeta do Sul e Zero Hora).

\footnotetext{
${ }^{2}$ O planejamento pode seguir o que traz Antunes (2003, p. 115-116): planejar; escrever; e revisar e reformular, caso necessário.
} 
- Um locutor lê e os demais colegas de grupo escutam.

- Análise das condições de produção e das características do gênero, seguindo roteiro passado pelo professor.

Momento 2: Leitura de textos escritos por alunos de mesmo nível escolar

- Leitura em grupo.

- Elenco escrito das características do gênero.

- Roda de conversa para reflexão oral a partir de roteiro proposto.

O professor conduz a roda de conversa, levantando questionamentos: Sobre o que trata o texto? Quais os assuntos abordados? Quem é o autor? De que lugar fala? A quem se destina o texto? Quem lê? Quando foi escrito? Onde ele poderia ser veiculado/publicado? Em que suporte (TV, revista, jornal, internet)?.

Momento 3: Análise linguística com enfoque nos aspectos verbais

- Selecionar os verbos que transparecem ações e discutir sobre os aspectos verbais (de acordo com o sentido que os verbos expressam no texto).

- Observar qual o tempo verbal que se repete nos textos de opinião e qual a ideia que acrescentam ao texto.

- Analisar a construção do ponto de vista nos textos, observando outros recursos linguísticos, além do emprego verbal.

- Reescrever o texto, alterando o tempo verbal para o passado a fim de observar se caberia ou não este tempo a este gênero textual.

Momento 4: Produção de artigo assinado para divulgação

- Proposta de produção textual individual, com tema "celular" e no gênero artigo assinado, podendo necessitar de reescrita após avaliação do professor.

Momento 5: Divulgação do material

- Divulgação do material dos alunos em blog e/ou em painel na escola.

\section{Considerações finais}

Nossos estudos apontaram para uma possível proposta de intervenção em aulas de Português, proporcionando o estudo da língua através de textos do gênero artigo assinado, analisando linguisticamente o uso dos aspectos verbais. A proposta 
envolveu momentos de leitura/escuta, de oralidade, de análise linguística e de produção textual. A avaliação do trabalho não foi incluída como um tópico à parte, pois acreditamos que o envolvimento de professor e alunos, em todos os cinco momentos (propostos na intervenção), será grande e suficiente para compreender como o aspecto verbal pode representar um traço característico de tal gênero.

Concordamos que as categorias de tempo e aspecto são utilizadas na língua de forma entrelaçada e devem ser examinadas como categorias semânticas e discursivas, como verdadeiros processos enunciativos e de construção de sentido. $O$ aspecto é fenômeno relacionado a eventos ou ações verbais que, para preencher o sentido, pode contar com o apoio de modalizadores e/ou de adjuntos adverbiais.

É certo que tempo e aspecto são muito relevantes à significação do texto. Importa verificar em que medida eles contribuem para a construção de sentido e o quanto refletem a intenção do sujeito ao utilizar tais tempos e aspectos para se comunicar, representando o poder de argumentação, ou seja, revelando a intenção, que pode ser a de trazer os fatos para a realidade, prolongar os fatos no tempo, ou persuadir, convencer, enfim, influenciar aquele com quem estabelecemos interação.

A língua materna, tomada enquanto discurso, resultado de interações em dado contexto social, usufrui de recursos gramaticais e, conforme a intenção de uso, tais recursos gramaticais contribuem para formar as relações de sentido pretendidas. Portanto, em uma proposta de intervenção no ensino de língua materna, é muito relevante que se considere leitura/escuta e produção, mas também muito importante é a análise linguística de fenômenos gramaticais para que se domine o uso da gramaticalidade da língua, a fim de escrever de maneira a dar o sentido que desejamos, considerando também, é claro, o veículo de divulgação, o público alvo e demais condições de produção.

\section{Referências}

ANTUNES, I. Aula de português: encontro \& interação. São Paulo: Parábola Editorial, 2003.

AZEREDO, J. C. de. Gramática Houaiss da Língua Portuguesa. São Paulo: Publifolha, 2013.

BAKHTIN, M. Estética da criação verbal. Tradução de Paulo Bezerra. São Paulo: WMF Martins Fontes, 2011 [1979, 1992, 2003]. 
BEZERRA, M. A; REINALDO, M. A. Análise linguística: afinal, a que se refere? São Paulo: Cortez, 2013.

BORTONI-RICARDO, S. M. Nós cheguemu na escola, e agora?: sociolinguística \& educação. São Paulo: Parábola Editorial, 2005.

BRASIL. Secretaria de Educação Fundamental. Parâmetros curriculares nacionais: terceiro e quarto ciclos do ensino fundamental: língua portuguesa. Brasília: MEC/SEF, 1998.

CASTILHO, A. T. de. Nova gramática do Português brasileiro. 1. ed. 3. reimp. São Paulo: Contexto, 2014.

GERALDI, J. W. (Org.) O texto na sala de aula. São Paulo: Anglo, [1982]2012.

MAIESKI, M. N. O gênero do discurso artigo como objeto de ensinoaprendizagem: uma proposta de integração da prática de produção textual à leitura e à análise linguística. Dissertação (Mestrado) - Programa de Pós-Graduação em Linguística, Universidade Federal de Santa Catarina. Florianópolis, 2005.

MARCUSCHI, L. A. Gêneros textuais definição e funcionalidade. In: DIONÍSIO, A. P.; MACHADO, A. R.; BEZERRA, M. A. (Orgs.). Gêneros textuais \& ensino. Rio de Janeiro: Lucerna, 2002, p. 19-36.

MENDONÇA, M. Pontuação e sentido: em busca da parceria. In: DIONÍSIO, A. P.; BEZERRA, M. A. O livro didático de Português: múltiplos olhares. Rio de Janeiro: Lucerna, 2005, p. 113-125.

MENEGASSI, R. J. Professor e escrita: a construção de comandos de produção de textos. Universidade Estadual de Campinas, Instituto de Estudos da Linguagem. Trabalhos em Linguística Aplicada. Campinas, no 42, 55-79, Jul./Dez. 2003.

Disponível em: http://www.escrita.uem.br/escrita/pdf/rmenegassi1.pdf

NEVES, M. H. de M. Gramática de usos do Português. São Paulo: UNESP, 2000.

RODRIGUES, N. C. A construção dialógica do discurso do professor de língua portuguesa. São Carlos: Pedro \& João Editores, 2011.

RODRIGUES, R. H. O artigo jornalístico e o ensino da produção escrita. In: ROJO, R. (Org.). A prática de linguagem em sala de aula: praticando os PCNs. São Paulo: EDUC; Campinas, SP: Mercado das Letras, 2001, p. 207-220.

TRAVAGLIA, L. C. Gramática: ensino plural. São Paulo: Cortez, 2003.

VARGAS, M. V. Verbo e práticas discursivas. São Paulo: Contexto, 2011.

WACHOWICZ, T. C. Análise linguística nos gêneros textuais. São Paulo: Saraiva, 2012. 
Artigo recebido em: 10 de agosto de 2015

Artigo aprovado em: 01 de março de 2016

\section{Sobre as autoras:}

Lenir Maria Rossarola é Graduada em Letras - Português e respectivas literaturas (UFSM); especialista em TICs na Promoção da Aprendizagem, em Mídias na Educação e em Gestão Escolar (UFRGS); e, mestranda no curso de Mestrado Profissional em Letras - PROFLETRAS (UFSC). Atuação como professora de Língua Portuguesa e Literatura Brasileira (1996 - 2014), como responsável por Laboratório de Informática de Escola (2002 - 2008) e como professora supervisora do Programa Institucional de Bolsas de Iniciação à Docência - PIBID na Universidade de Santa Cruz - UNISC (2010 - 2013). Foi diretora da Escola Estadual de Educação Básica João XXIII (2002 - 2003) e coordenadora do Núcleo de Tecnologia Educacional de Santa Cruz do Sul (2006 - 2009).

Nara Caetano Rodrigues possui graduação em Letras (1990), mestrado em LetrasLinguística (1997), doutorado em Linguística pela Universidade Federal de Santa Catarina-UFSC (2009) e pós-doutorado pela Universidade Estadual de CampinasUNICAMP (2014). Atualmente é professora de Língua Portuguesa no Colégio de Aplicação do Centro de Ciências da Educação da Universidade Federal de Santa Catarina e faz parte do corpo docente do PROFLETRAS da UFSC. Tem experiência na área de Língua Portuguesa e Linguística, com ênfase em Linguística Aplicada, atuando principalmente nos seguintes temas: ensino de língua portuguesa, gêneros discursivos, análise dialógica do discurso e formação de professores. Atuou como formadora no GESTAR II-SC/RS/2010-2011. A fundamentação teórica de referência provém dos estudos do Círculo de Bakhtin. 